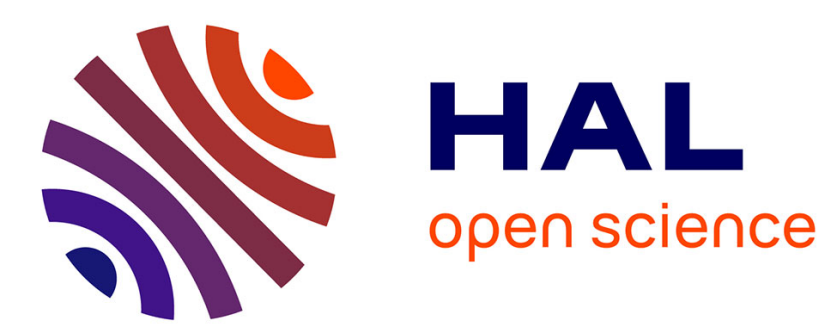

\title{
Sublethal effects of oxalic acid on Apis mellifera (Hymenoptera: Apidae): changes in behaviour and longevity
}

\author{
Saskia Schneider, Dorothea Eisenhardt, Eva Rademacher
}

\section{To cite this version:}

Saskia Schneider, Dorothea Eisenhardt, Eva Rademacher. Sublethal effects of oxalic acid on Apis mellifera (Hymenoptera: Apidae): changes in behaviour and longevity. Apidologie, 2012, 43 (2), pp.218-225. 10.1007/s13592-011-0102-0 . hal-01003525

\section{HAL Id: hal-01003525 \\ https://hal.science/hal-01003525}

Submitted on 1 Jan 2012

HAL is a multi-disciplinary open access archive for the deposit and dissemination of scientific research documents, whether they are published or not. The documents may come from teaching and research institutions in France or abroad, or from public or private research centers.
L'archive ouverte pluridisciplinaire HAL, est destinée au dépôt et à la diffusion de documents scientifiques de niveau recherche, publiés ou non, émanant des établissements d'enseignement et de recherche français ou étrangers, des laboratoires publics ou privés. 


\title{
Sublethal effects of oxalic acid on Apis mellifera (Hymenoptera: Apidae): changes in behaviour and longevity
}

\author{
Saskia SchneIDER, Dorothea EISENHARdt, Eva RAdEMAcher \\ Institute of Biology/Neurobiology, Freie Universität Berlin, Königin-Luise-Str. 28-30, 14195 Berlin, Germany
}

Received 25 March 2011 - Revised 19 August 2011 - Accepted 27 September 2011

\begin{abstract}
Oxalic acid dehydrate (OA) in the application form of trickling (3.5\% solution) has shown a good bee tolerance. However, negative long-term effects of the treatment on honeybees are expected. The sublethal effects of OA on division of labour, activity, olfactory learning and the longevity of Apis mellifera were studied. Newly emerged workers were treated with $3.5 \%$ OA solution by topical application (dosage $175 \mu \mathrm{g} / \mathrm{bee}$ ) and introduced into a colony. Behavioural observations were carried out and the longevity of every worker was recorded. To investigate the learning behaviour, foragers were trained in a classical olfactory conditioning paradigm, the olfactory conditioning of the proboscis extension response. These experiments revealed sublethal effects of $\mathrm{OA}$ on Apis mellifera. The treatment caused a significant decrease in worker activity, nursing behaviour and longevity. Treated bees also showed significantly more self-grooming and a higher response in the olfactory conditioning than bees of the control group.
\end{abstract}

Apis mellifera / oxalic acid / sublethal effects / behaviour / longevity

\section{INTRODUCTION}

Oxalic acid is the active ingredient of approved drugs used for the treatment of Apis mellifera L. against the parasitic mite Varroa destructor. Concerning acute toxicity, the substance is well-tolerated by the bees (Rademacher and Harz 2006). So far, there are only few studies investigating sublethal effects of acaricides on honeybees. Negative effects on brood development 3-4 months after the last application of oxalic acid were described by Higes et al. (1999). Moosbeckhofer (2001) also assumed long-term effects of the treatment due to a reduced fitness of treated colonies, although they had no increased mortality.

Corresponding author: E. Rademacher, radem@zedat.fu-berlin.de

Manuscript editor: Monique Gauthier
Pesticide studies revealed how sublethal dosages of an ingredient can affect honeybees. This includes changes in the division of labour, a reduced level of hive-cleaning and increased selfgrooming (Thompson 2003). In some studies, the treatment with pesticides led to an increased motor activity and impaired long-term retention of olfactory learning (Weick and Thron 2002; Abramson et al. 2004; Decourtye et al. 2004; El Hassani et al. 2008; Desneux et al. 2007; Aliouane et al. 2009). Pesticide treated worker bees also had a reduced longevity (Desneux et al. 2007). The effect of acaricides on worker lifespan is so far only investigated for Apistan ${ }^{\circledR}$ and formic acid only: no differences in lifespan between the treated and untreated bees were found (Birnie 1997). Effects of oxalic acid on the longevity of honeybees are not yet described.

In this study, sublethal effects of the treatment with oxalic acid on behaviour and lon- 
gevity of Apis mellifera were investigated and the following questions answered:

1. Does OA have an effect on the age-related appearance or the intensity of the in-hive behaviour of worker bees?

2. Are there differences in the learning performance during olfactory condition between treated and untreated bees?

3. Will there be an influence on longevity after the treatment?

\section{MATERIAL AND METHODS}

\subsection{Recruitment and treatment of young bees}

To recruit test animals at the same age, a brood frame was removed from a hive 1 day before the workers hatched and kept in an incubator (Memmert INB 400 , Schwabach, Germany) at $30.5^{\circ} \mathrm{C}$ and $65 \%$ RH. After 24 h, 300 newly emerged workers were marked with different colours and numbers and treated individually with a solution of $3.5 \%$ oxalic acid dehydrate (OA; $0.035 \mathrm{~g}$ oxalic acid dehydrate in $1 \mathrm{ml}$ Aqua dest). A drop of $5 \mu \mathrm{L}$ was applied to the ventral side of the abdomen with an air displacement pipette (Roth, Karlsruhe, Germany). This corresponds to $175 \mu \mathrm{g} \mathrm{OA} / \mathrm{bee}$, the average dosage a single bee would receive at colony treatment according to the approval for $\mathrm{OA}$ in Germany. The control group received water instead. A few hours later, when the applied acid had dried, the young workers were introduced to an outdoor observation hive with two vertical frames, a population of approximately 2,000 bees and a mated queen. Sealed and open brood as well as honey and pollen were always present during the observation period. After the observation period of 19 days, it was necessary to replace one brood frame to avoid overcrowding.

\subsection{In-hive behaviour observation}

The test and control groups consisted of 150 individually treated bees each, so that a total of 300 bees were introduced into the observation hive. The monitoring of behaviour started when bees were 1 day old and ended after 19 days. Only the data of bees which were alive on this day were analysed (138 in test and 144 in control groups).

The animals were observed every day between 9 and 12 o'clock by the "point and scan sampling" method (Altmann 1984). Bees were chosen randomly from the group of marked bees at the beginning of the observation period. They were monitored one after another and their first shown behavioural patterns were recorded. If a bee was standing or walking, it was watched for a total of $10 \mathrm{~s}$ to be sure that it was not involved in another task. The number of behavioural events per day generally consisted of the activity from several bees. Behavioural patterns were categorized after Crailsheim et al. (1996) and Pfeiffer and Crailsheim (1999).

The following patterns could be clearly identified and their data allowed a statistical evaluation and verification: self-grooming, inactivity, nursing, trophallactic interactions, house-cleaning, honey manipulation, patrolling.

Following patterns were just recorded in context of activity: wax manipulation, nibbling on broodcaps, aggressive behaviour, visiting empty cell, visiting pollen- and honeycells, interactions with queen and other activities included various behaviours such as flight and dancing.

\subsection{Longevity}

The lifespan of all bees of the test and control groups was recorded. The moment of death was defined as the day the bee was found dead in or outside the hive. Data acquisition started the first day of behavioural observations and ended when every focal bee was considered dead. Because of outside conditions, many bees disappeared during the observation time without being found dead, so their time of death was defined as 1 day after the last day the animal was detected for the last time during data acquisition.

\subsection{Olfactory conditioning}

The olfactory learning of the honeybee can be studied under controlled laboratory conditions by using olfactory Pavlovian conditioning of the proboscis extension response (PER; Bittermann et al. 1983; Menzel 1999). Conditioning was carried out as described in Felsenberg et al. (2011). 
In the morning, returning foragers of uncontrolled age carrying pollen were caught in front of a hive and treated individually with $3.5 \% \mathrm{OA}$ (test group) or water (control group). Six groups of test and control bees, each group containing 20 animals were prepared for the conditioning. The bees were immobilized by cooling and harnessed in metal tubes with a strip of tape between the head and the thorax. In the afternoon, all bees were fed to satiation to ensure an equal motivation. They were kept overnight in darkness in a container.

A classical olfactory conditioning trial consisted of a temporal pairing of a clove oil odour (5-s presentation) as conditioned stimulus and the successive presentation of sucrose $(1.25 \mathrm{M})$ to the antennae and the proboscis (4-s presentation) as unconditioned stimulus. The presentation of the conditioned and unconditioned stimulus overlapped for $2 \mathrm{~s}$. The animals received three conditioning trials with an intertrial interval of $10 \mathrm{~min}$. In the retention test, the conditioned stimulus was presented alone for $5 \mathrm{~s}$, and the animals responding with a PER were noted and calculated for each group. All animals were fed to satiation $1 \mathrm{~h}$ after each retrieval test and also every afternoon with $0.88 \mathrm{M}$ of sucrose solution. After the experiments, every animal was tested for its response to sucrose solution to assure its ability of proboscis extension.

\subsection{Data analysis}

To compare the behavioural patterns of the test and control bees over the period of 19 days, the paired absolute data of the test and control groups were analysed with the Wilcoxon's signed-rank test. Therefore, the data were approximated by randomisation for each day so that the number of bees was equal in both groups. Every data of age-related behaviour was checked for normal distribution (SigmaStat ${ }^{\circledR} 3.0$ ) then analysed with the general method of moments (GMMs). The curve progressions of the age-related behaviour from the two groups were only compared for normal distributed data using a rate and proportion analysis (SigmaStat (B) 3.0). The longevity analysis was accomplished with a Kaplan-Meier survival analysis, where the survival curves of the groups were tested for significant differences with the Gehan-Breslow test (SigmaStat ${ }^{\circledR}$ 3.0).

For statistical analysis of the olfactory conditioning, a two-way repeated measurement ANOVA (SigmaStat ${ }^{\circledR} 3.0$ ) was used. When the $p$ values were significant, a pairwise comparison between all groups was performed with Fisher LSD Method (SigmaStat (B) 3.0). The numbers of bees showing a conditioned PER in the retention test were compared with the chisquared test between groups (Microsoft ${ }^{\circledR}$ Excel 2002). For all tests, a level of significance of $P \leq$ 0.05 was defined.

\section{RESULTS}

\subsection{In-hive behaviour observation}

During the observations of the behaviour, all age-related behavioural patterns of the workers appeared in the natural chronology: bees of both groups started showing first events of behavioural patterns for nursing, honey or pollen manipulation, wax manipulation and patrolling at the same time but in different intensity. The bees started showing all age-related behavioural patterns somewhat earlier. Of the age-related data, only honey or pollen manipulation had normal distribution. Analysis with GMM showed a similarly slight positive skewness of $S=0.12$ for test and $S=0.17$ for control bees. With the rate and proportion analysis, no differences of curve progression of both groups could be detected.

However, treated bees showed an increased self-grooming, a superior tendency to inactivity and decreased nursing behaviour (Figure 1). These results could be statistically verified with a $p$ value of $P \leq 0.005$ (Wilcoxon, one-tailed). For all other behavioural patterns including trophallactic interactions, house-cleaning, honey manipulation and patrolling, there were no significant differences between the test and the control groups. During the observation of the in-hive behaviour, precipitate foraging was not observed in both groups except for one test and two control bees, when bees were ten, respectively 11 days old. 


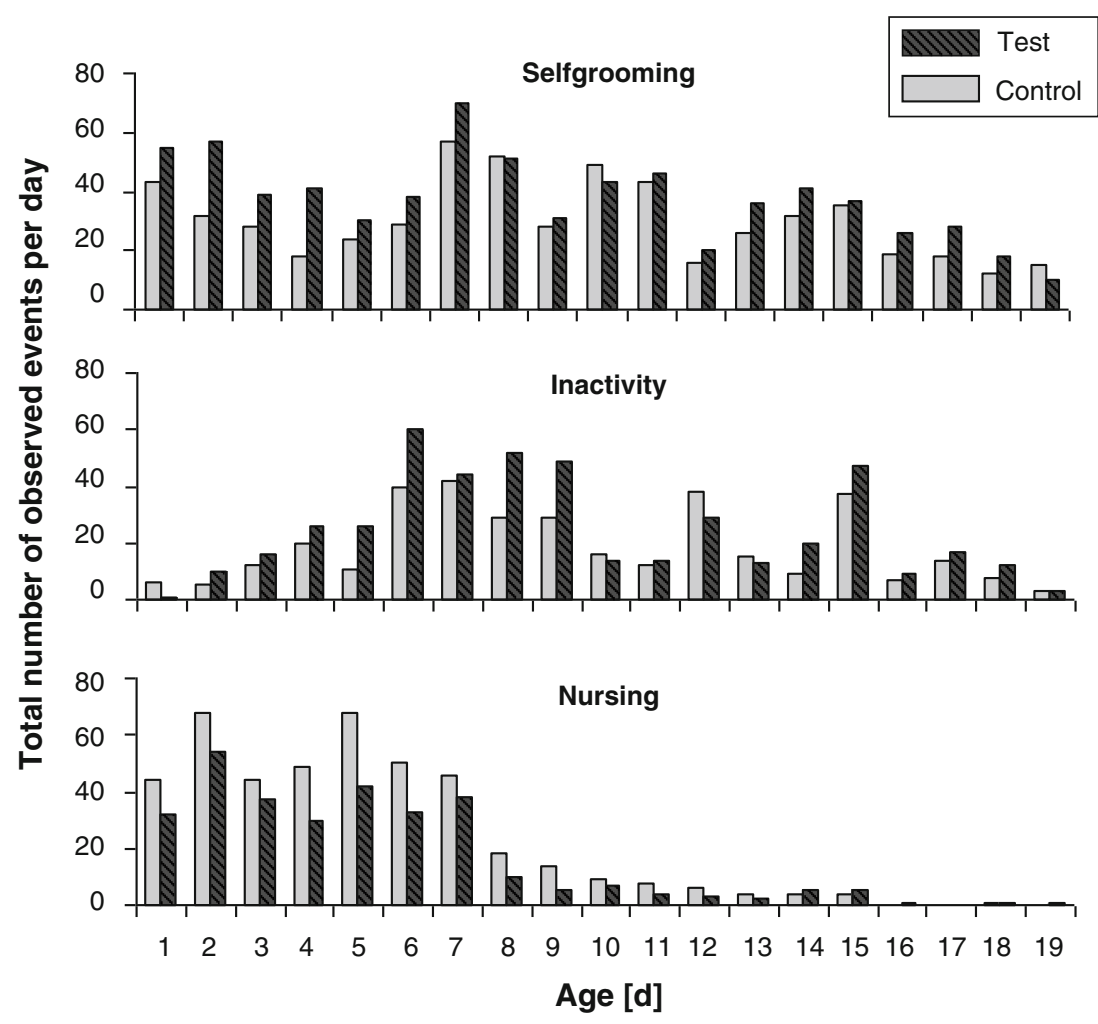

Figure 1. Total number of behavioural events observed per day: self-grooming, inactivity, nursing.

Due to the increased self-grooming of the treated workers, which often wiped off their abdomen with their hind legs, five freshly emerged bees were treated with $\mathrm{OA}$ and checked for residues of the acid under the binocular after $24 \mathrm{~h}$. Crystals were found on the abdomen and in higher amounts on the metatarsi of the hind legs (Figure 2). Equal residues were not detected on the control bees, so it is highly expected that these crystals on the treated bees are residues of OA.

\subsection{Longevity}

During the time of the experiment, the number of test bees decreased more rapidly than the controls. Between the average (12.98 \pm 7.06 for test and $16.08 \pm 6.49$ for control bees) and median (13 for test and 16 for control bees) of the survival data of both groups was a difference of 3 days. The survival curve of the test bees shows a more rapid decrease (Figure 3) with a significant difference to the control group at the level of $P \leq 0.001$ (Gehan-Breslow test). These results suggest that the treatment with OA led to a reduced lifespan.

\subsection{Olfactory conditioning}

The treatment with OA caused an increase of animals' performance during learning. This effect could be already recognized during the second trial of acquisition (A2), where the amount of test bees extending the proboscis was almost $20 \%$ higher than in the controls (Figure 4). For the aquisition phase, there were significant differences both between the acquisition trials (A1-A3) (ANOVA, $P \leq 0.001, F=$ 40.912, $\mathrm{DF}=167)$ and between the test and control groups (ANOVA, $P \leq 0.005, F=8.367$, $\mathrm{DF}=167)$. The highest percentage of test bees extending the proboscis in the test group compared to the control group could be statis- 


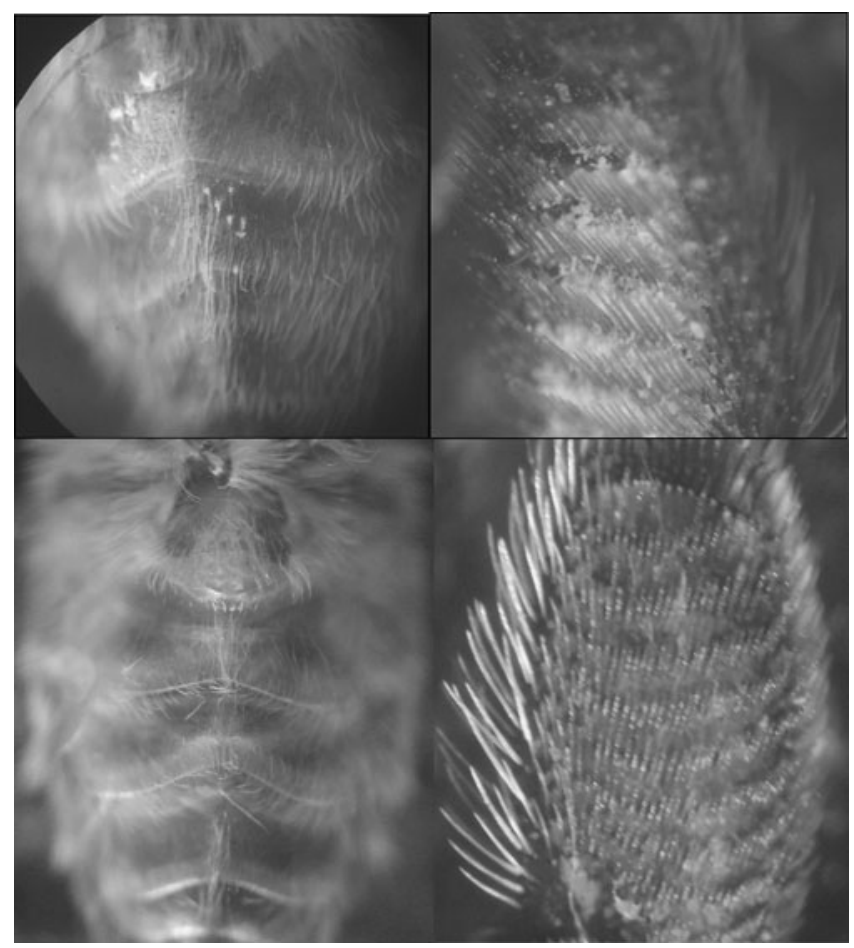

Figure 2. Above: crystalline residues on the abdomen (left) and metatarsus (right) of a treated bee; below: abdomen (left) and metatarsus (right) of a control bee without residues.

tically confirmed for the second and third trial (Fisher LSD post hoc test, $P \leq 0.005$ ).

Testing memory retention $24 \mathrm{~h}$ after learning demonstrated a significant difference between the test and the control group as revealed by a chi-squared test $\left(\chi^{2}=3.85, P \leq\right.$ $0.05, \mathrm{DF}=1)$ : retention performance was sig- nificantly higher in the test group than in the controls (Figure 4).

\section{DISCUSSION}

Treatment with a $3.5 \%$ solution of oxalic acid dehydrate (OA), corresponding to the dosage of

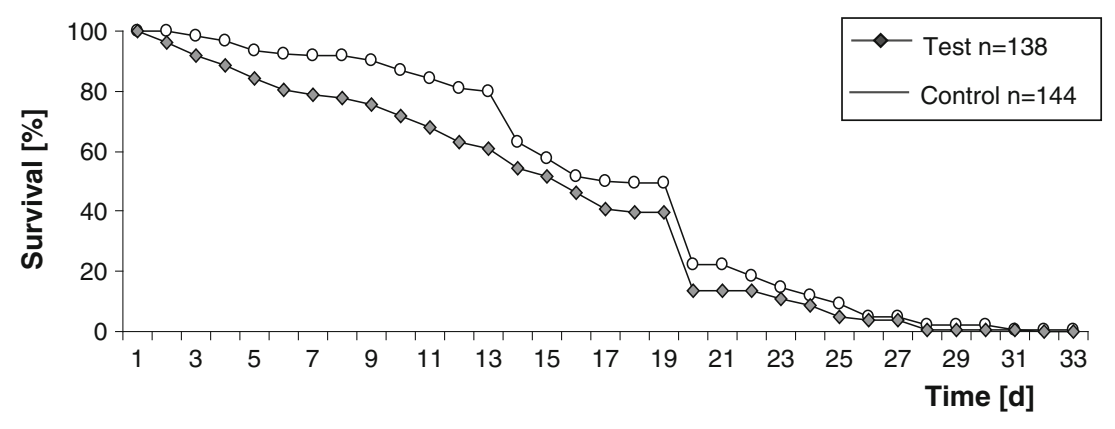

Figure 3. Survival curves of test and control bees (the curve drops down at day 19 due to a necessary comb change). 


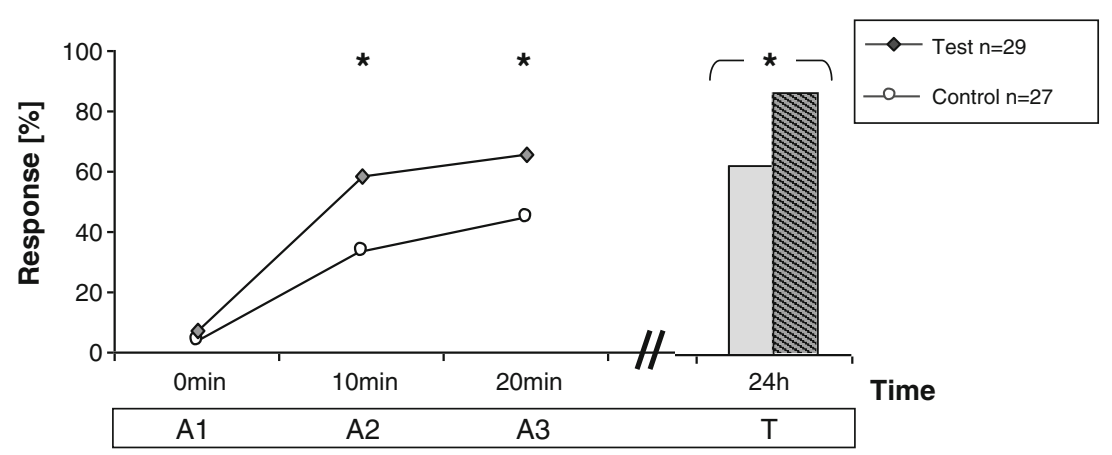

Figure 4. Olfactory learning $(A 1-A 3)$ of bees $24 \mathrm{~h}$ after OA treatment. Animals were tested $24 \mathrm{~h}$ after learning with the trained odour $(T)$. (Asterisks) Significant differences between test and control group during acquisition (ANOVA $p=0.005, F=8.367, \mathrm{DF}=167$; post hoc test: Fisher LSD $p \leq 0.005$ ) and $24 \mathrm{~h}$ after learning in the retention test $\left(\chi^{2}=3.85, P \leq 0.05, \mathrm{DF}=1\right)$.

$175 \mu \mathrm{g} / \mathrm{bee}$, causes sublethal effects on $A$. mellifera. The decreased activity and nursing as well as the reduced lifespan of treated bees are aspects for a permanent damage due to the treatment with OA.

A decreased activity was also noticed in other studies where bees were numb for several hours (24-48 h) post application of $50 \mathrm{~mL} \mathrm{4.2 \%}$ oxalic acid per colony (Bacandritsos et al. 2007). Similar effects are known from bees treated with formic acid. Due to the fact that the animals did not recover from their immobility, permanent neurotoxic damage was assumed (Bolli et al. 1993). Concerning OA treatment comparable damage may have caused the decreased tasks performance in the colony, including nursing.

The increased self-grooming of the treated workers could be caused by the detected residues of OA on bee surface. While drying, OA forms crystals which can be found on the animals' abdomen (Aliano et al. 2006). In our observations, treated bees often stroked over the abdomen with their hind legs. Residues of OA could explain the increased grooming at least for the first days of observation. The increased selfgrooming during the whole observation period could also be a symptom of poisoning. Those symptoms were observed for other toxic substances, i.e. permethrin (Cox and Wilson 1984).
It is known that a treatment with $\mathrm{OA}$ can cause permanent lesions in digestive and excretory organs (Martin-Hernandez et al. 2007). Gregorc and Smodis Skerl (2007) detected necrotic cell death in $69 \%$ of bee midgut cells $24 \mathrm{~h}$ after an oral treatment with $3 \%$ OA (dosage $600 \mu \mathrm{g} / \mathrm{bee}$ ). Tissue distribution of the acid was detected in bees that received a dermal application (dosage $1,320 \mu \mathrm{g} / \mathrm{bee}$ ), so it was assumed that some of the acid is ingested by the bee (Martin-Hernandez et al. 2007). The dosages used in these experiments were higher than the dosage of $175 \mu \mathrm{g} / \mathrm{bee}$ used in the present study. However, a damage of the digestive and excretory organs of the test bees in the experiment cannot be excluded. This could have caused an insufficient resorption of nutriments through the epithelium of the gut resulting in a weakening of the bees.

This assumption is supported by the results from harnessed honeybees. In this paradigm, the OA-treated bees show a significantly different behavioural performance in the acquisition phase and the memory test than the control bees. Although the behavioural performance of the control bees is rather low, compared with other studies (Stollhoff and Eisenhardt 2009; Felsenberg et al. 2011), this demonstrates a facilitating effect of $\mathrm{OA}$ on the conditioned response. In contrast to the sublethal effects of 
pesticides described for imidacloprid and diflubenzuron or the organophosphate compound coumaphos, which all produced lower levels of acquisition (Weick and Thron 2002; Abramson et al. 2004; Decourtye et al. 2004; Aliouane et al. 2009), the test bees showed a higher performance during acquisition and retention test. These results might indicate a higher motivation of treated bees during learning, which could be caused by hunger due to an insufficient resorption of nutriments released on the damage of the digestive organs induced by the OA treatment.

It has been demonstrated before that the level of satiation is critical for acquisition and memory formation (Friedrich et al. 2004). In addition, there were similar results with hunger stressed bees after infection with Nosema (Mayack and Naug 2009). Also bees infected with other diseases like Deformed Wing Virus, showed an increased learning performance (Iqbal and Mueller 2007). However, whether the treatment with OA actually has an effect on the ingestion of food and therefore causes hunger and thus a motivational difference remains to be shown.

OA treatment affects the general condition of bee colonies: the workers' performance is restrained due to the changes in behaviour, the decreased nursing of brood can lead to a lack of healthy and vital workers and the decreased lifespan could modify demographic alterations in colony age structure. Under the suggestion, that the treatment will cause damage of the digestive organs, such bees would be weaker and less vital. This could influence the general state of health of whole colonies.

In colony treatment, $\mathrm{OA}$ is applied during November/December when brood is absent and the in-hive tasks performance and foraging are reduced. However, due to its stable residues, OA remains in the colony for longer periods and is expected to be found in springtime (Moosbeckhofer 2001 personal communication). So the sublethal effects of OA on the behaviour and lifespan of the individual honeybee, documented in this study, can also be supposed in the colony situation.
Regardless to the findings of this study, the advantages of $\mathrm{OA}$ as a treatment against the mite $V$. destructor still outweigh the possible negative consequences to the honeybee colony and it should remain as one of the main varroacides.

\section{ACKNOWLEDGEMENTS}

Thanks to Johannes Felsenberg for his support on the olfactory conditioning experiments. I also thank Mr. Friedrichowitz for his support as an apiculturist with the experimental procedure.

Effets subléthaux de l'acide oxalique sur Apis mellifera (Hymenoptera: Apidae): modifications du comportement et de la longévité.

Apis mellifera / acide oxalique / effet subléthal / comportement / longévité

Sublethaleffekte von Oxalsäure auf Apis mellifera (Hymenoptera: Apidae): Verhaltensänderungen und Lebenserwartung.

Apis mellifera / Oxalsäure / sublethale Effekte / Verhalten / Lebenserwartung

\section{REFERENCES}

Abramson, C.I., Squire, J., Sheridan, A., Mulder, P.G. (2004) The effect of insecticides considered harmless to honey bees (Apis mellifera): Proposcis conditioning studies by using the insect growth regulators tebufenozide and diflubenzuron. Environ. Entomol. 33(2), 378-388

Aliano, N.P., Ellis, M.D., Siegfried, B.D. (2006) Acute contact toxicity of oxalic acid to Varroa destructor (Acari: Varroidae) and their Apis mellifera (Hymenoptera: Apidae) hosts in laboratory bioassays. J. Econ. Entomol. 99(5), 1579-1582

Aliouane, Y., el Hassani, A.K., Gary, V., Armengaud, C., Lambin, M., Gauthier, M. (2009) Subchronic exposure of honeybees to sublethal doses of pesticides: Effects on behavior. Environ. Toxicol. Chem. 28(1), $113-122$

Altmann, J. (1984) Observational sampling methods for insect behavioral ecology. Fla. Entomol. 67(1), 5056 
Bacandritsos, N., Papnastasiou, I., Saitanis, C., Nanetti, A., Roinioti, E. (2007) Efficacy of repeated trickle applications of oxalic acid in syrup for varroosis control in Apis mellifera: Influence of meteorological conditions and presence of brood. Vet. Parasitol. 148(2), 174-178

Birnie, L.C. (1997) Sublethal effects of three acaricide treatments on honey bee (Apis mellifera L.) colony development and honey production, Simon Fraser University Library Surrey, [online] http://ir.lib.sfu. ca/handle/1892/8485 (accessed on 9 July 2008)

Bittermann, M.E., Menzel, R., Fietz, A., Schafer, S. (1983) Classical-conditioning of proboscis extension in honeybees (Apis mellifera). J. Comp. Psychol. 97 (2), 107-119

Bolli, H.K., Bogdanov, S., Imdorf, A., Fluri, P. (1993) Zur Wirkungsweise von Ameisensäure bei Varroa jacobsoni Oud. und der Honigbiene (Apis mellifera L.). Apidologie 24(1), 51-57

Cox, R.L., Wilson, W.T. (1984) Effects of permethrin on the behavior of individually tagged honey bees, Apis mellifera L. (Hymenoptera: Apidae). Environ. Entomol. 13(2), 375-378

Crailsheim, K., Hrassnigg, N., Stabentheiner, A. (1996) Diurnal behavioural differences in forager and nurse honey bees (Apis mellifera carnica Pollm.). Apidologie 27(4), 235-244

Decourtye, A., Armengaud, C., Renou, M., Devillers, J., Cluzeau, S., Gauthier, A., Pham-Delegue, M.H. (2004) Imidacloprid impairs memory and brain metabolism in the honeybee (Apis mellifera L.). Pestic. Biochem. Physiol. 78(2), 83-92

Desneux, N., Decourtye, A., Delpuech, J.-M. (2007) The sublethal effects of pesticides on beneficial arthropods. Annu. Rev. Entomol. 52, 81-106

El Hassani, A.K., Dacher, M., Gary, V., Lambin, M., Gauthier, M., Armengaud, C. (2008) Effects of sublethal doses of acetamiprid and thiamethoxam on the behavior of the honeybee (Apis mellifera). Arch. Environ. Contam. Toxicol. 54(4), 653-661

Felsenberg, J., Gehring, K., Antemann, V., Eisenhardt, D. (2011) Behavioural pharmacology in classical conditioning of the proboscis extension response in honeybees (Apis mellifera), J. Vis. Exp. 47, [online] http://www.jove.com/index/Details.stp?ID=2282 doi: $10.3791 / 2282$
Friedrich, A., Thomas, U., Müller, U. (2004) Learning at different satiation levels reveals parallel functions for the cAMP-protein kinase A cascade in formation of long-term memory. J. Neurosci. 24(18), 44604468

Gregorc, A., Smodis Skerl, M.I. (2007) Toxicological and immunohistochemical testing of honeybees after oxalic acid and rotenone treatments. Apidologie $\mathbf{3 8}$ (3), 296-305

Higes, M., Meana, A., Suárez, M., Llorente, J. (1999) Negative long-term effects on bee colonies treated with oxalic acid against Varroa jacobsoni Oud. Apidologie 30(4), 289-292

Iqbal, J., Mueller, U. (2007) Virus infection causes specific learning deficits in honeybee foragers. Proc. Roy. Soc. B-Biol. Sci. 274(1617), 1517-1521

Martin-Hernandez, R., Higes, M., Perez, J.L., Nozal, M. J., Gomez, L., Meana, A. (2007) Short term negative effect of oxalic acid in Apis mellifera iberiensis. Span. J. Agric. Res. 5(4), 474-480

Mayack, C., Naug, D. (2009) Energetic stress in the honeybee Apis mellifera from Nosema ceranae infection. J. Invertebr. Pathol. 100(3), 185-188

Menzel, R. (1999) Memory dynamics in the honeybee. J. Comp. Physiol. [A] 185, 323-340

Moosbeckhofer, R. (2001) Varroabekämpfung mit Oxalsäure im Träufelverfahren. Bienenvater 12, 7-12

Pfeiffer, K.J., Crailsheim, K. (1999) The behaviour of drifted nurse honey bees. Insectes Soc. 46(1), 34-40

Rademacher, E., Harz, M. (2006) Oxalic acid for the control of varroosis in honey bee colonies - a review. Apidologie 37(1), 98-120

Stollhoff, N., Eisenhardt, D. (2009) Consolidation of an extinction memory depends on the unconditioned stimulus magnitude previously experienced during training. J Neurosci. 29(30), 9644-9650

Thompson, H.M. (2003) Behavioural effects of pesticides in bees-Their potential for use in risk assessment. Ecotoxicology 12(1-4), 317-330

Weick, J., Thron, R.S. (2002) Effects of acute sublethal exposure to coumaphos or diazinon on acquisition and discrimination of odor stimuli in the honey bee (Hymenoptera: Apidae). J. Econ. Entomol. 95(2), 227-236 